\title{
LOS COLECTIVOS DE VÍCTIMAS Y EL ACCESO A LA JUSTICIA EN MÉXICO
}

Groups Of Victims And Access To Justice In Mexico

\section{Fátima Esther Martínez Mejía}

Universidad Autónoma del Estado de México,Toluca de Lerdo, Méx., México. ORCID: https://orcid.org/0000-0003-2882-4346

E-mail: fatimaemmejia@hotmail.com

\section{Mónica Natalia Martínez Mejía}

Universidad Autónoma del Estado de México.Toluca de Lerdo, Méx., México.

ORCID: https://orcid.org/0000-0001-9432-3342

E-mail: nataliammejia@gmail.com

Trabalho enviado em 15 de janeiro de 2022 e aceito em 17 de janeiro de 2022

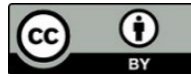

This work is licensed under a Creative Commons Attribution 4.0 International License. 


\section{RESUMEN}

El presente trabajo estudia la incidencia de los colectivos de víctimas en el acceso a la justicia, la toma de decisiones y la reducción de la inseguridad en México. Para ello resulta imperante revisar el artículo 17 constitucional en lo relativo a la prohibición de que ninguna persona podrá hacerse justicia por sí misma, en el cual se garantiza el derecho a que se administre justicia por tribunales, y no admite excepciones en ninguna circunstancia. Con base en un enfoque en derechos humanos utilizando el método analítico y la investigación documental se hace una reflexión sobre la sociedad civil organizada como un sujeto político, que muchas veces ha suplido las funciones estatales de búsqueda y localización de personas desaparecidas. Se pretende averiguar si en los límites de la democracia participativa la ciudadanía puede acceder a la justicia de una forma horizontal y así influir en la vida pública del país. La respuesta es afirmativa, la actuación de los colectivos de víctimas ofrece loables resultados que marcan un camino para la defensa y promoción de los derechos humanos, los derechos de las víctimas y la visibilización de las personas desaparecidas producto del fracaso del Estado mexicano en materia de seguridad pública.

Palabras clave: colectivos de víctimas; participación ciudadana; acceso a la justicia; seguridad pública; personas desaparecidas.

\section{ABSTRACT}

This paper studies the impact of groups of victims on access to justice, decision making and the reduction of insecurity in Mexico. To this end, it is imperative to review Article 17 of the Mexican Constitution in relation to the prohibition that states that no person may take justice into his own hands, which guarantees the right to have justice administered by the courts, a right that admits no exceptions under any circumstances. Relying on a rights-based approach, a question emerges on organized civil society as a political subject, which has often supplanted the state functions of searching and locating disappeared people. The aim is to find out if, within the limits of participatory democracy, citizens can have access to justice in a horizontal way and thus influence the public life of the country. The answer is affirmative, the actions of the groups of victims offer laudable results that mark a path for the defense and promotion of human rights, groups of victims and the visibility of disappeared people resulting from the failure of the Mexican State in the public security field.

Keywords: groups of victims; citizen participation; access to justice; public security; disappeared people. 


\section{INTRODUCCIÓN}

En las últimas décadas, México se ha convertido en uno de los países más violentos derivado del crimen organizado, el tráfico de drogas, la trata de personas, entre otros. Esta desgracia es la consecuencia de la incapacidad del Estado de proteger a la ciudadanía de la criminalidad en aumento e ilustra la fuerte crisis en materia de seguridad pública. La desaparición de los 43 estudiantes de Ayotzinapa, Guerrero; la masacre de la comunidad migrante en San Fernando, Tamaulipas; la apropiación violenta de la industria aguacatera por parte de la delincuencia organizada en Michoacán; el incremento nacional de los feminicidios y, demás lamentables sucesos son una parte de las atrocidades vividas por miles de personas. En 2019 se registró el año más violento en el país con 34,582 homicidios dolosos, el más alto en 20 años de registro oficial (SESNSP, 2019). El Consejo Ciudadano para la Seguridad Pública y la Justicia Penal (2021) denotó que México fue el epicentro mundial de la violencia homicida, en el Ranking 2020 de las 50 ciudades más violentas del mundo, 18 fueron mexicanas, pero siete estuvieron entre las diez más peligrosas: Celaya, Tijuana, Ciudad Juárez, Ciudad Obregón, Irapuato, Ensenada y Uruapan.

El Informe de Seguridad emitido por la Secretaría de Seguridad y Protección Ciudadana (2021) reveló que de enero a mayo de 2021 se contuvo la tendencia al alza del homicidio doloso, con una disminución del 2.9\% respecto al año anterior. Los estados de Guanajuato, Baja California, Jalisco, Estado de México, Michoacán y Chihuahua concentraron el 50.4\%, que representó un total de 14,243 víctimas de este delito. El año 2021 se terminó con un crecimiento en la incidencia delictiva nacional del 10.9\% lo que representó que de enero a noviembre se denunciaron 1 millón 871 mil 808 ilícitos, en comparación con 1 millón 687 mil 660 en 2020 (SESNSP, 2021). A lo que se le suma, el escaso acceso a la justicia ofrecido por el Estado lo que coloca a las víctimas en una situación de desconfianza y frustración por la limitada asistencia jurídica, la tardanza en resultados formales, así como la falta de seguimiento en las investigaciones en materia forense y desaparición de personas. Lo anterior se traduce en que las instituciones tanto de seguridad pública, administración y procuración de justicia como las comisiones estatales de derechos humanos y las áreas de atención a víctimas han sido incapaces, negligentes y omisas frente a las exigencias de las personas que recurren a ellas. 
A nivel general se percibe una desconfianza y corrupción en las instituciones policiacas y judiciales, que se agudizada por los altos niveles de impunidad. La denuncia ciudadana se ha vuelto el lugar menos recurrido por quienes adolecen estos fenómenos ${ }^{1}$. La sociedad mexicana ha advertido continuamente que el gobierno en su nivel municipal, estatal y federal ha sido indolente en sus funciones de seguridad, así como en algunos casos su colusión con el crimen organizado ${ }^{2}$. Ante tal panorama, es un hecho el nacimiento de organizaciones que, a pesar de no contar con los recursos suficientes muestran la capacidad de generar propuestas para cubrir los vacíos de poder. Para Banqués Quesada (2011, p.115) lo natural es que la gente no se quede cruzada de brazos cuando no se le han cubierto las condiciones mínimas de seguridad, así surgen alternativas que mezclan espontaneidad en contextos de supervivencia y el frío cálculo racional de circunstancias extremas.

Frente a la violencia que arrasa al país, el Estado mexicano debe recomponer sus interacciones con la sociedad para realizar un verdadero cambio de paradigma institucional, que robustezca el estado de derecho constitucional. Esta modificación implica dos grandes transiciones con el objetivo de fortalecer los espacios democráticos respetuosos de los derechos fundamentales para construir una sociedad más incluyente, libre de discriminación y violencia. La primera, se refiere a consolidar el sistema jurídico en lo relativo a la impartición de justicia con los más altos estándares en derechos humanos. Este elemento se vio vigorizado con la reforma al artículo primero constitucional de junio de 2011, de suerte que "se inició el llamado neoconstitucionalismo mexicano al contemplar una cláusula de apertura al Derecho Internacional de los Derechos Humanos que rompió con el monopolio interpretativo de los órganos jurisdiccionales internos y constitucionalizó los estándares internacionales" (FLORES Y URIBE, 2014, p. 108).

La segunda transición involucra la superación del argumento que asume que la política es una actividad exclusiva del Estado, la cual "forma parte del imaginario político de la modernidad que acompaña la existencia del Estado nacional, soberano y territorialmente delimitado, que se configura y difunde mundialmente entre los siglos XVI y XX" (ROUX, 2002, p. 232). La complejidad de las sociedades contemporáneas demanda reconfigurar dicha posición para que el Estado apoyado por la ciudadanía (agente político de cambio) corrija las insuficiencias en distintas materias, principalmente

\footnotetext{
1 Véase MÉXICO EVALÚA; CENTRO DE ANÁLISIS DE POLÍTICAS PÚBLICAS. Hallazgos 2018: Seguimiento y Evaluación del Sistema de Justicia Penal en México. México: 2019. Disponible en: https://www.mexicoevalua.org/mexicoevalua/wp-content/uploads/2020/03/hallazgos2018-3.pdf

${ }^{2}$ En la Recomendación No. 23VG/2019, la Comisión Nacional de Derechos Humanos (CNDH) reconoció que en México las desapariciones son un problema estructural donde confluyen la impunidad, la violencia, la inseguridad y colusión de las autoridades de los tres niveles de gobierno con la delincuencia organizada como fue el caso de las fosas clandestinas en San Fernando, Tamaulipas.
} 
la seguridad pública. Por supuesto, esta intervención deberá ser de conformidad con la ley, en las competencias correspondientes y bajo el principio democrático.

Bajo la democracia participativa la sociedad civil debe ser consultada para el diseño de políticas públicas, así como un vínculo para presentar propuestas de leyes y protocolos. Ambas acciones debieran funcionar como herramientas para que una auténtica transformación se imprima en el esquema social mexicano con el único propósito de robustecer las obligaciones estatales de prevenir, proteger, garantizar y respetar los derechos humanos. De donde se infiere que, la ciudadanía puede contribuir por medio de su participación legal, entre muchos otros desafíos, a la reducción de la inseguridad pública en el país.

De acuerdo con los últimos estudios en materia de seguridad pública en México se observan dos escenarios diferentes. Por un lado, se desarrolla un importante incremento de grupos armados activos principalmente en la zona de Guerrero, dividido en forma de: a) crimen organizado y b) autodefensas y policías comunitarias. Estas últimas como respuesta para llenar los huecos de poder frente a la incapacidad del Estado de ofrecer seguridad pública. Por el otro, existe una notable emergencia de organizaciones de víctimas, que en forma de colectivos están incidiendo en la toma de decisiones que corresponden al Estado en materia de seguridad pública, desaparición de personas y construcción de la paz. Es decir, los colectivos de víctimas están demostrando un gran pragmatismo al colaborar con las fuerzas estatales para avanzar en sus causas (CRISIS GROUP, 2020).

La impetuosidad de los colectivos de víctimas reafirma la idea de que el Estado debe dejar de ser visto como el único ente que puede hacer política. Enrique Dussel arguye que cada nuevo movimiento social emprende la organización necesaria para una lucha por la democracia y una participación política simétrica diferenciada. Estos nuevos actores, antes considerados como "pasivos", subjetivan su posición y se tornan activos en un renovado, ampliado y cualitativamente profundizado campo político democrático (DUSSEL, 2002, p. 221). Los colectivos de víctimas son una manifestación del ejercicio valiente de un sector de la ciudadanía que actuando conforme a la ley se convierte en un sujeto político capaz de cambiar realidades adversas. De ahí la urgencia que las instituciones estatales escuchen la voz colectiva que ha sido silenciada por estructuras verticales de poder que han examinado los hechos a la distancia.

En este aspecto, resulta imperante revisar el artículo 17 constitucional en lo relativo a la prohibición de que ninguna persona podrá hacerse justicia por sí misma y, en el cual se garantiza el derecho a que se le administre justicia por tribunales, mismo que no admite excepciones en ninguna circunstancia. Con base en un enfoque en derechos humanos utilizando el método analítico y la 
investigación documental se hace una reflexión sobre la sociedad civil organizada como un sujeto político, que muchas veces ha suplido las funciones estatales de búsqueda y localización de personas desaparecidas. Se pretende averiguar si en los límites de la democracia participativa la ciudadanía puede acceder a la justicia de una forma horizontal y así incidir en la vida pública del país. La respuesta es afirmativa, la actuación de los colectivos de víctimas ofrece loables resultados que marcan un camino para la defensa y promoción de los derechos humanos, los derechos de las víctimas y la visibilización de las personas desaparecidas producto del fracaso, incapacidad y ausencia del Estado mexicano en materia de seguridad pública, aseveración que será demostrada a continuación.

En cuanto al contenido del artículo se inicia con la generalidad de que el Estado es el único ente que puede monopolizar la violencia legitima constitucionalizada. En seguida se analiza la posibilidad de que la ciudadanía organizada se empodere como sujeto político gracias a la democracia participativa, de ahí que pueda coadyuvar en la vigencia de los derechos humanos y el acceso a la justicia. Se hace referencia a la crisis de seguridad pública y la privatización de la violencia en México con repercusiones en materia de desaparición forzada y forense. Se expone la incidencia de los colectivos de víctimas de la inseguridad y cómo sus acciones han suplido las obligaciones del Estado mexicano en distintas áreas. Finalmente, se enfatiza que en términos reales el papel de la Guardia Nacional ha sido insuficiente para pacificar al país.

\section{LA RAZÓN DE SER DEL ESTADO Y LA SEGURIDAD}

En su origen, el Estado moderno guarda su razón de ser en el aseguramiento de la tranquilidad pública, que abarca el otorgar paz y seguridad a la sociedad. La finalidad de esta organización humana es el cuidado de su propia conservación para el logro de una vida más armónica (HOBBES, 2010, p. 137-144). La formación del Estado fue el camino para que las personas pudieran defenderse y perpetuarse ante la hostilidad del "estado de naturaleza" en el que se hallaban, donde la satisfacción de las propias necesidades y la voluntad se anteponían. El uso indiscriminado de la fuerza y el poder imperaban, los seres humanos se reducían a lo más vil, brutal y antisocial. Se vivía en permanente conflicto: "estado de guerra"

[...] porque los fuertes que tienen el poder desean más poder con el afán de asegurar el poder que ya tienen y los débiles buscarán constantemente la manera de resistirse a ese poder que los somete y priva de la satisfacción de sus exigencias. Aunque puedan lograrse acuerdos bajo esta situación, siempre serán provisionales y frágiles, porque - dice Hobbes- toda asociación cimentada sobre 
el poder del más fuerte no puede nunca ser ni sólida ni duradera (CARRILLO CASTILLO, 2002, p. 262).

Fue a través de un pacto con reglas y orden que la humanidad superó el "estado de naturaleza", la sociedad aceptó someterse a la autoridad del soberano, cuya concentración del poder legítimo obligó a los súbditos a ceder la posibilidad de hacerse justicia por sí mismos. La razón de ser del Estado hobbesiano se condicionó al cumplimiento de proteger a la comunidad política, así el poder civil monopolizó la fuerza: la violencia legítima constitucionalizada y se convirtió en garante de la paz social, el orden público y la seguridad; y el ente que salvaguarda tanto el derecho a la vida, la integridad, la libertad y la propiedad, como los deberes de las personas para con las demás en su calidad de ciudadanas en un estado de derecho.

A más de tres siglos de la publicación del Leviathan, la sociedad se ha convertido en un conjunto de interacciones globales de distinta índole y con consecuencias diversas, que requieren la intervención de todos los Estados como es el tema del medioambiente. Sin embargo, la inseguridad pública o la construcción de la paz tienen que resolverse en términos de soberanía, independientemente de la ayuda internacional que los países puedan recibir. Por ejemplo, la Suprema Corte de Justicia de la Nación ha reconocido el carácter vinculante de las Acciones Urgentes emitidas por el Comité contra la Desaparición Forzada de la ONU, así como la competencia de éste para examinar quejas individuales, pero ha indicado que el trabajo de la agencia estatal no puede ser sustituido, al contrario, tiene que afianzarse para corregir las deficiencias institucionales. En esta tesitura, la Oficina del Alto Comisionado de las Naciones Unidas para los Derechos Humanos (s/f) promueve que no solo se fortalezcan las instituciones de seguridad para que los Estados cumplan con sus obligaciones internacionales en materia de derechos humanos, sino también se atienda la urgencia de empoderar a las víctimas y las organizaciones de la sociedad civil para contribuir en la mejora de escenarios públicos que garanticen los derechos fundamentales.

\section{EL ACCESO A LA JUSTICIA EN MÉXICO}

En materia de seguridad pública la prohibición constitucional de hacerse justicia por sí mismo es un precepto jurídico que sintetiza la evolución de las formas jurídicas para tener acceso a la justicia de manera institucional. La Constitución Política de los Estados Unidos Mexicanos asienta en el primer párrafo del artículo 17, que "Ninguna persona podrá hacerse justicia por sí misma, ni ejercer violencia para reclamar su derecho", además "toda persona tiene derecho a que se le administre justicia por 
tribunales que estarán expeditos para impartirla en los plazos y términos que fijen las leyes, emitiendo sus resoluciones de manera pronta, completa e imparcial". La disposición normativa en comento se enlaza con lo dispuesto por el artículo 21 constitucional, el cual indica que la seguridad pública es una función del Estado que comprende la prevención, investigación y persecución de los delitos, así como la sanción de las infracciones administrativas. Aunado a dicha responsabilidad estatal, se contempla el derecho a poseer armas en el domicilio de los habitantes del país para su seguridad y legítima defensa, con excepción de las prohibidas por la ley y las de uso exclusivo de la Fuerza Armada permanente y los cuerpos de reserva, expresado en el artículo 10 constitucional.

El artículo 17 de la Ley Fundamental se convierte en un requisito sine qua non para justificar la razón de ser del Estado como el único ente capaz de preservar el orden y seguridad pública, paz social, prohibir la violencia y arbitrariedad entre particulares, por consiguiente, no admite excepciones en ninguna circunstancia. Se argumenta que aun y cuando la función estatal de garantizar la seguridad pública en México no ha sido cumplida satisfactoriamente, no puede considerarse que en el instante en que deje de ejecutarse, la prohibición de hacerse justicia por sí mismo pierda su razón de ser, pues se estaría en contra del estado de derecho y la justicia social. Existe, empero la posibilidad que el acceso a la justica se realice de manera horizontal bajo el auspicio de la democracia participativa, donde la propia ciudadanía es la que emprende acciones, dentro del esquema legal y democrático para subsanar las deficiencias del Estado, tal como ocurre con las operaciones de los colectivos de víctimas de la inseguridad.

\section{LA PARTICIPACIÓN CIUDADANA EN LA SEGURIDAD PÚBLICA}

En el curso de la democracia participativa y la iniciativa ciudadana las personas cada vez más toman parte de los asuntos públicos, están vigilantes de la actuación de la autoridad y coadyuvan en asegurar la vigencia de los derechos humanos. Bajo distintas modalidades como la participación no institucionalizada, sectorial, temática y comunitaria ${ }^{3}$, la sociedad organizada se posiciona como un sujeto político, que ejerce sus derechos sin afectar el orden legal, la tranquilidad pública ni los derechos de terceros. Alfonso Torres Carrillo precisa que "en la medida que la acción colectiva define su identidad, conquista su autonomía frente a otros actores, elabora proyectos y visiones de futuro propios y se consolida como fuerza social con capacidad de incidir sobre las esferas públicas donde se definen y construyen sus intereses" (TORRES CARRILLO, 2005, p. 12), pasa de ser un sujeto social para

\footnotetext{
${ }^{3}$ Véase la Ley de Participación Ciudadana de la Ciudad de México.
} 
convertirse en un sujeto político. Para sustentar este planteamiento es menester el apoyo de la tesis de Enrique Dussel, quien esboza que el principio formal de legitimidad de la política es el denominado "principio democrático", que

[...] legítima toda institución o acción política que se haya decidido desde el reconocimiento de todos los miembros de la comunidad política como iguales, libres y autónomos, con voluntad fraterna, y cuyas resoluciones prácticas hayan sido el fruto del consenso (y de la voluntad común) como conclusión de argumentos racionales y honesta tolerancia, y no por dominación o violencia, es decir, habiendo efectuado todos los procedimientos teniendo en cuenta el criterio de la participación simétrica de los afectados. Habiendo tomado parte el sujeto político, el ciudadano en último término, en todas las decisiones, éstas lo obligan (normatividad propia de la soberanía como origen del dictado y como destinatario de la obligación) no solo a la realización (performance) de lo acordado, sino igualmente a asumir la responsabilidad de las consecuencias de dichas decisiones (como instituciones o acciones) (DUSSEL, 2002, p. 210).

La organización de la sociedad civil muestra un escenario muy alentador en México, ya que refleja los postulados que promueve la categoría denominada Juicio Democrático latu sensu en su vertiente no estatal, la cual arguye la capacidad de la ciudadanía para intervenir de una forma más activa en algunos asuntos públicos con la consecuente revisión y contrastación del paradigma teórico que limita su participación respecto al ejercicio del acceso a la justicia (ORDÓÑEZ, 2017). Mediante el cuestionamiento al aparato de Estado, la participación ciudadana se convierte en una posible solución sin contravenir la prohibición constitucional de que ninguna persona puede hacerse justicia por sí misma al proceder dentro del marco democrático y legal con los recursos jurídicos proporcionados por el sistema estatal.

El Estado ha fijado límites y mecanismos de acción para que la ciudadanía pueda defender sus derechos humanos ante posibles amenazas, delitos y violaciones. Gracias a que se asiste de un sistema político democrático y participativo, la visión de seguridad se encuentra vinculada a la idea de acción ciudadana (CONSEJO MEXICANO DE LAS CIENCIAS SOCIALES, 2016). A través de ordenamientos como la Ley de Participación Ciudadana de la Ciudad de México o la Ley para la prevención social de la violencia y la delincuencia, con Participación Ciudadana del Estado de México se estipula el derecho individual o colectivo de intervenir e incidir en las decisiones públicas, cuyo objetivo es cooperar con las autoridades para mejorar las condiciones de seguridad. 


\section{LA CRISIS DEL ESTADO MEXICANO EN MATERIA DE SEGURIDAD PÚBLICA}

La crisis de Estado en materia de seguridad pública tiene su origen más cercano en las políticas calderonistas iniciadas en el 2006 con la "guerra contra el narcotráfico", estrategia que tuvo resultados desastrosos. George W. Grayson (2010) narró el derramamiento de sangre relacionado con los cárteles mexicanos de la droga, las decapitaciones, castraciones y crímenes de la delincuencia organizada que destruyeron a comunidades enteras, algunas aniquiladas y otras obligadas al desplazamiento. Para organismos como Human Rights Watch, el expresidente Calderón

[...] No sólo no logró contener a las poderosas organizaciones delictivas que operan en el país, sino que además generó un incremento dramático de las graves violaciones de derechos humanos cometidas por miembros de las fuerzas de seguridad a las cuales se encomendó la misión de enfrentar a esas organizaciones. En vez de reforzar la seguridad pública, estos abusos exacerbaron el clima de violencia, caos y temor (HUMAN RIGHTS WATCH, 2013a).

En el sexenio de Enrique Peña Nieto, con diferencias mínimas al de Calderón, la prevención se mantuvo en el marco del discurso y se continuó con la estrategia punitiva de combate y lucha frontal contra el crimen organizado por medio de la militarización (SÁNCHEZ ESPINOZA Y JUÁREZ JAIMES, 2019 , p. 247). Durante este periodo la crisis de derechos humanos se agudizó: las desapariciones, la fabricación de acusaciones, la impunidad, las ejecuciones extrajudiciales, las detenciones arbitrarias, las torturas, las numeras agresiones y homicidios de periodistas y personas defensoras de derechos humanos se normalizaron; al igual que la corrupción a nivel federal. Eventos trágicos como los casos en Tlatlaya, Nochixtlán, Ayotzinapa o Tanhuato demostraron, como lo informó Human Rights Watch (2013b) que la estrategia de Peña Nieto de utilizar a las fuerzas armadas por sí solas fueron incapaces de restablecer el estado de derecho y seguridad ciudadana, en particular si parte del personal de la institución castrense fue quien cometió las violaciones a los derechos humanos.

El actual presidente Andrés Manuel López Obrador recibió una herencia negra en inseguridad, su política de "abrazos no balazos" ha implicado que los organismos de seguridad no se confronten directamente con el crimen organizado con el objetivo de evitar masacres como los vistos en sexenios anteriores. A la mitad de su periodo, el mandatario ha subrayado que en el país hay paz, gobernabilidad y no existe riesgo de inestabilidad, no obstante, hay espacios sin ley ni autoridad como se observa en 
"Chiapas al borde de la guerra civil"4. Para el presidente su gobierno confronta el flagelo de la violencia a diario, a pesar de que sus adversarios magnifiquen la violencia política, pero según él esta no obedece a la realidad (LÓPEZ OBRADOR, 2021a). Aunque, la violencia política vivida en las elecciones de 2021 dejó 91 personas políticas asesinadas, 14 fueron mujeres, 860 víctimas de diversos delitos y 910 agresiones contra personas políticas, aspirantes y candidatas a cargos de elección popular (ETELLEKT CONSILTORES, 2021). López Obrador ha manifestado que tiene "confianza que vamos a seguir avanzando hasta pacificar al país, es un desafío, es una responsabilidad, es una convicción. Si no terminamos de pacificar a México por más que se haya hecho, no vamos a poder acreditar históricamente a nuestro gobierno" (LÓPEZ OBRADOR, 2021b). Sin embargo, la realidad muestra que la violencia no se contiene, al contrario, crece cada día más. Los y las mexicanas estrenamos el año 2022 con calles marcadas con sangre y un clima de violencia y violaciones a los derechos humanos:

[...] Las recientes masacres en Zacatecas el 6 de enero (10 cuerpos encontrados frente al Palacio de Gobierno) y en Veracruz, el 7 de enero ( 9 cuerpos arrojados en una carretera del sur del estado) y el 8 (cuatro personas asesinadas en Rinconada, a $45 \mathrm{~km}$. de Xalapa), no permiten albergar el mínimo de esperanza de que la paz, la seguridad y la tranquilidad sean posibles en el corto plazo en México (SALDAÑA FLORES, 2022).

De acuerdo con la información entregada por la Fiscalía General de la República y las fiscalías estatales, en el periodo 2006 al 7 de abril de 2021 el número de reportes de personas desaparecidas o no localizadas fue de 85,006 . Los reportes de diciembre de 2018 al 7 de abril de 2021 señalan que las entidades federativas con el mayor número de personas desaparecidas fueron: Jalisco, Michoacán, Ciudad de México, Tamaulipas, Nuevo León, Sonora, Sinaloa, Zacatecas y Estado de México, que concentraron el 76\% del total (ENCINAS, 2021). El 6 de octubre de 2021 la Comisionada Nacional de Búsqueda de Personas Desaparecidas, Karla Quintana Osuna compareció ante el Senado de la República y declaró que por primera vez el Estado mexicano reconoció (desde diciembre de 2018) tanto la crisis en materia de desaparición como la crisis forense. Asimismo, la funcionaria dio cuenta que el Registro Nacional de Personas Desaparecidas y No Localizadas (RNPDNL) mostró un total de 97,794 personas desaparecidas y no localizadas entre el periodo de 1964 al 4 de octubre de 2021 , sin

\footnotetext{
${ }^{4}$ Véase EJÉRCITO ZAPATISTA DE LIBERACIÓN NACIONAL. Comunicado del Comité Clandestino Revolucionario Indígena-comandancia General del Ejército Zapatista de Liberación Nacional, Chiapas al borde de la Guerra Civil, 19 de septiembre de 2021. Disponible en: https://enlacezapatista.ezln.org.mx/2021/09/19/chiapas-al-borde-dela-guerra-civil/
} 
embargo, esta cifra puede ser más alta en virtud de la desconfianza en denunciar por parte de la ciudadanía 5 .

Por otro lado, México está sumido en una profunda crisis forense que se traduce en "registros dispersos, incompletos, contradictorios o fragmentados de los gobiernos estatales y del federal [que] obligan a las familias a vivir en la incertidumbre sobre el paradero de sus seres queridos. La suma de negligencias y omisiones condenan a las personas desaparecidas a desaparecer por segunda vez" (GUILLÉN, TORRES Y TURATI, 2018). El problema es tan agudo que se verifica con las "inhumaciones irregulares realizadas por las autoridades, cuerpos y fragmentos son un claro indicador de la ausencia del Estado. A esto se suma el deficiente trabajo en la preservación de muestras de ADN. Todo ello redunda en el casi nulo resultado en identificaciones positivas" (INSTITUTO MEXICANO DE DERECHOS HUMANOS Y DEMOCRACIA, 2019, p. 147).

El 25 de septiembre de 2018 se dieron a conocer públicamente dos "tráileres de la muerte" constituidos como morgues itinerantes en el estado de Jalisco. El primero albergó 322 cuerpos y el segundo oficialmente 49 cuerpos, dato cuestionado por familiares de víctimas ya que siguió operando hasta noviembre. Durante un periodo de tiempo uno de los contenedores frigoríficos deambuló por la Zona Metropolitana de Guadalajara, Ilamando la atención de la población por el olor nauseabundo debido a la falta de refrigeración (FRANCO; GONZÁLEZ; TAPIA Y VARGAS, 2020). La alerta ciudadana reveló "Ios secretos del colapso forense, y se descubrió también el destino de al menos 35 personas reportadas como desaparecidas, de las que las autoridades decían desconocer su paradero, pero tenían en su poder" (FRANCO; GONZÁLEZ; TAPIA, GALLARDO Y VARGAS, 2020). La negligencia y la deshumanización de las autoridades jaliscienses representó el aletargamiento, el abandono y la indolencia estatal frente al dolor de las familias de víctimas, que cada vez son más combativas.

\section{LOS GRUPOS ARMADOS Y LA INSEGURIDAD PÚBLICA EN MÉXICO}

Mario A. Loborie Iglesias destaca que la constitución de agentes armados no estatales es el gran reto sobre el monopolio exclusivo de la fuerza del Estado, el autor se apoya de la tesis de Robert Mandel al exponer que la privatización de la violencia no solo desafía la supremacía del modelo de Estado-nación, sino también la distribución del poder, la soberanía, la disuasión y la independencia (LOBORIE IGLESIAS, 2011, p. 30). Los grupos armados como el crimen organizado florecen en Estados

\footnotetext{
5 Véase COMISIÓN NACIONAL DE BÚSQUEDA. Versión Pública RNPDNO. 2021. Disponible en: https://versionpublicarnpdno.segob.gob.mx/Dashboard/Index
} 
débiles con un alto porcentaje de corrupción y colusión entre las autoridades y los entes ilegales, imponen sus propias reglas en las poblaciones y embisten con una gran fuerza armamentista. Entre los ejemplos de la incursión del crimen organizado en la vida privada de las personas está el "impuesto criminal" producto de las extorsiones del Cártel Jalisco Nueva Generación en regiones como Michoacán o Colima. ${ }^{6}$

En México la oleada de violencia expresada en homicidios, secuestros, desapariciones, extorciones, robos y la desconfianza en las instituciones de seguridad han mostrado que las autoridades se han visto rebasadas al enfrentar la privatización de la violencia y no controlar ni cohesionar el monopolio de la fuerza, como resultado los huecos de poder han sido tomados por actores armados. Esto ha provocado el surgimiento de autodefensas y un mayor auge de policías comunitarias, ambas expresiones son un llamado grupal a la defesa y protección del derecho a la vida y la seguridad ante la ausencia y omisión del Estado.

Las policías comunitarias se fundamentan en el derecho de los pueblos indígenas de autogobierno parcial y autonomía en administración de la justica formulado en el artículo 2 de la Constitución Política de los Estados Unidos Mexicanos. La Ley de Reconocimiento, Derechos y Cultura de los Pueblos y Comunidades Indígenas del Estado de Guerrero las define como cuerpos de seguridad pública reconocidos, de conformidad con los sistemas normativos de las comunidades y pueblos indígenas. En lo relativo a las autodefensas, organizaciones de civiles armados, según Enrique Guerra Manzo fueron constituidas en Michoacán desde el 2013 por la falta de voluntad política y la incapacidad de las autoridades para garantizar los derechos humanos de la ciudadanía ante la escalada de violencia producida por grupos como el Cartel de los Caballeros Templarios o el Cártel de Jalisco Nueva Generación (GUERRRA MANZO, 2015, p. 10).

El informe La guerra cotidiana: Guerrero y los retos a la paz en México resalta que las policías comunitarias parecen ser una idea de regulación acorde con los requerimientos de la región, sin embargo, son una expresión de autodefensa que se ha extendido más allá de sus competencias legales y territoriales originales, porque varias se han desviado de la meta de proteger a su ciudadanía. El problema resulta más intrincado al entremezclarse los grupos criminales con algunas de ellas, donde sus límites son poco claros, no solo por sus orígenes, sino por su forma de operar de manera estratégica, pues utilizan las mismas armas que los entes ilegales, contratan exmilitares, manipulan la

\footnotetext{
${ }^{6}$ Véase PAREDES, Heriberto. Michoacán: una comunidad en armas. México: México Evalúa, 14 de septiembre 2021. Disponible en: https://www.mexicoevalua.org/michoacan-una-comunidad-en-armas-para-plantarplatanos/
} 
violencia con fines propagandísticos, desmiembran los cuerpos de sus enemigos y lo suben a redes sociales, más aún emplean métodos parecidos a los insurgentes como los coches bomba. Además, se les ha acusado de abuso de poder, detenciones arbitrarias y fachadas para intereses ilícitos (CRISIS GROUP, 2020).

Si bien, hay policías comunitarias y autodefensas legítimas como las que combaten las extorsiones o defienden la industria local del plátano o el aguacate en Michoacán existen otras que con sus acciones violentas se colocan como un fenómeno quebrantador del pacto social que viola derechos humanos, especialmente de la niñez. Uno de los casos de mayor dolor ha sido en Guerrero, cuando en abril de 2021 la policía rural de la Coordinadora Regional de Autoridades ComunitariasPueblos Fundadores (CRAC-PF) presentó un video en el que se observa con armas de fuego la integración a sus filas de una niña y 31 niños de entre 6 y 11 años. Su justificación fue expuesta por un niño comunitario: "iFirmes ya, embrazar armas ya! Si no hay leyes que nos protejan a los niños huérfanos de México ni gobierno de nuestro país para [sic] que nos brinden seguridad, entonces vamos a responder con fuego a los sicarios hijos de la chingada" (OCAMPO ARISTA, 2021). Actos como el señalado no solo indignan, sino que reclaman que el Estado retome la seguridad para que la tarea de proteger deje de ser privada y vuelva a manos públicas. Cabe señalar que estas instancias son incapaces de garantizar los derechos humanos y la gobernabilidad, dado que el gobierno es el responsable del diagnóstico, diseño y ejecución de políticas públicas en materia seguridad.

\section{LOS COLECTIVOS DE VÍCTIMAS Y EL ACCESO A LA JUSTICIA DE FORMA HORIZONTAL}

Los colectivos de víctimas han estado activos desde la "guerra sucia" (1969-1979)7, como el Comité Eureka, pero a partir de la "guerra contra el narcotráfico" el fenómeno de las desapariciones aumentó y cientos de familias se han organizado en todo el territorio nacional para buscar a sus integrantes desaparecidos. Las acciones de las organizaciones de víctimas han ido más allá de la búsqueda de la justicia formal o legal (enjuiciamientos), pues se encaminan a la construcción de una justicia más cercana y humana, que combata la revictimización, conozca la verdad, garantice la no repetición, conserve la memoria, reciba las reparaciones y logre las reformas institucionales

\footnotetext{
${ }^{7}$ En palabras de defensores de derechos humanos plasmadas en Desde el corazón de la montaña se define a la guerra sucia como "la represión militar y política implementada por las corporaciones encargadas de la seguridad del Estado mexicano, destinadas a desmantelar los movimientos de oposición política y armada al régimen. Fue obra del Ejército. Las policías fueron meros auxiliares en las tareas de represión. Quienes implementaron las medidas para tratar de exterminar la insurgencia fueron, esencialmente, las Fuerzas Armadas" (HERNÁNDEZ NAVARRO Y BARRERA HERNÁNDEZ, 2020, p. 12).
} 
obligatorias para que la dignidad de las víctimas, sobrevivientes y familiares se reconozca y se proteja. Además, de exhibir tanto a las personas perpetradoras como a las instituciones involucradas y oponerse al negacionismo del Estado.

Las familias de personas desaparecidas tienen el derecho a exigir que se inicie de manera inmediata la búsqueda de la persona desaparecida; asesoría y representación durante la investigación o proceso penal; investigación diligente, efectiva, exhaustiva e imparcial sobre los hechos relacionados con la desaparición; acceso a mecanismos y procesos judiciales que garanticen el derecho a la verdad; conocer el alcance de los exámenes periciales; la toma de muestras de material genético para cotejo con posibles víctimas localizadas; recibir atención médica, psicológica y asistencia social; promover su incorporación a la vida social y económica; estar presentes en exhumaciones; contar con medidas de protección en caso de que su vida, integridad o libertad sean amenazadas o en riesgo; reparación del daño y el pago de tratamientos; atención de personas servidoras públicas de manera humana y digna; acceso a fondos de ayuda (COMISIÓN ESTATAL DE DERECHOS HUMANOS DE VERACRUZ, 2016).

Según Ana Cepeda y Salvador Leetoy las estrategias de estas organizaciones son manifestaciones de agencia que les permiten transcender su condición de víctimas y empoderarse como colectivos. Las acciones van desde la búsqueda, identificación de personas desaparecidas, entrenamiento en ciencias forenses (toma de ADN), recomendación de protocolos hasta asesoría en caso de desaparición, canalización de emociones derivadas de la tragedia y apoyo moral a familiares en esta situación (CEPEDA Y LEETOY,2021).

[...] Entre las actividades que suelen emprender, destacan el registro de casos que reciben directamente o que aparecen publicados en los medios, la realización de plantones en plazas y afuera de oficinas públicas, ruedas de prensa, difusión de casos en las redes sociales y la investigación del paradero de sus seres queridos. Del conjunto de acciones que han llevado a cabo estos grupos de familiares, identificamos aquellas que podrían orientarse hacia el tratamiento de la desaparición de personas como un problema público, que debe ser incluido en la agenda pública y sobre el que se debe diseñar una política pública integral. a) Registro y documentación de casos b) Denuncia pública c) Diálogo con autoridades d) Impulso de marcos legales e) Creación de redes (VILLARREAL MARTíNEZ, 2014, p. 115-116).

Son muchos los ejemplos de acciones colectivas que han surgido de demandas que confrontan al Estado, pero actúan bajo el marco institucional para acceder a la justicia. En el norte del país, en la región de Coahuila en 2013 se constituyó el colectivo Familias Unidas con los objetivos de a) buscar y 
localizar a personas desaparecidas, incluidas las que padecieron "La masacre de Allende" legalmente a las familias de víctimas; c) denunciar el control de los Zetas en la Prisión de Piedras Negras ${ }^{9}$ y, finalmente, d) documentar y responsabilizar al Grupo de Armas y Tácticas Especiales de la policía del Estado de Coahuila (GATE) de las arbitrariedades y las desapariciones de personas. Este colectivo se ha distinguido por contar con la asesoría jurídica de la abogada Ariana Denisse García Bosque, quien delineó una estrategia legal y coordinación con las y los integrantes del colectivo para operar frente al delito y las violaciones a los derechos humanos. Por medio del grupo de Búsqueda y Reacción Inmediata cada miembro llegó a cubrir tareas específicas, que abarcaron el trasladarse al Ministerio Publico, la cárcel municipal, el Centro Estatal de Control, Comando, Comunicaciones y Cómputo (C4) y el cuartel de Fuerza Coahuila (antes GATE y policía del estado); además de promover amparos para evitar posibles desapariciones por parte de las autoridades (SÁNCHEZ VALDÉS, PÉREZ AGUIRRE Y VERÁSTEGUI GONZÁLEZ, 2018). Estas labores repercutieron en la limitación de las intervenciones violentas del GATE, que fue eliminado con posterioridad.

El Movimiento por Nuestros Desaparecidos en México (MNDM) (2021) se conforma por más de 60 colectivos de familiares y organizaciones que buscan a personas desaparecidas en México y Centroamérica. Desde su fundación en 2015 el MVDM tuvo un fin político al relacionarse con los poderes Ejecutivo y Legislativo federal, al mismo tiempo de apoyarse en organismos internacionales y de la sociedad civil que, a través de marchas, eventos multitudinarios, recolecta de firmas, así como la denuncia internacional se hizo escuchar e influir en las y los tomadores de decisiones. Ello permitió que el MVDM transitara de ser un ente colectivo para convertirse en un sujeto político (CENTRO DE COLABORACIÓN CÍVICA, 2018, p. 44-47). El Movimiento tuvo como objeto primario influir e impulsar la aprobación de la norma vigente Ley en materia de desaparición forzada de personas, desaparición cometida por particulares y del Sistema Nacional de Búsquedas. Esta conquista colectiva de enorme alcance ha dado la posibilidad de que, a través del Consejo Nacional Ciudadano, los familiares de personas desaparecidas, personal especializado y representantes de organizaciones de derechos

\footnotetext{
${ }^{8}$ Véase THOMPSON, Ginger. Anatomía de una masacre. ProPublica; National Geographic, 12 de junio de 2017. Disponible en: https://www.propublica.org/article/allende-zetas-cartel-masacre-y-la-dea

${ }^{9}$ Entre 2010 y 2011 Coahuila fue un territorio controlado en su totalidad por el grupo criminal Los Zetas, cuyo cuartel se encontraba en la Prisión de Piedras Negras: "a) era un refugio seguro para los jefes Zeta que deseaban esconderse de los federales fuera de la nómina criminal; b) les servía para obtener ingresos vendiendo drogas, refrescos y chicharrones, cobrando cuotas por el uso de las celdas y rentando los cuartos utilizados para la visita conyugal; c) les proporcionaba un lugar discreto y seguro para instalar los compartimentos secretos en los automóviles que llevarían drogas a Estados Unidos; d) servía de base para reclutar sicarios; y, e) era un centro para confinar temporalmente a los secuestrados y para torturar, ejecutar y desaparecer cadáveres" (AGUAYO Y DAYÁN, 2018, p.7).
} 
humanos puedan realizar de manera formal acciones y medidas en tareas de búsqueda e investigación que conlleven al acceso a la justicia, la verdad, la reparación, la memoria y las garantías de no repetición.

El MNDM agrupa al Colectivo el Solecito de Veracruz (2021) instancia que se formó en 2014 como respuesta a la omisión del Estado frente a las desapariciones de personas, bajo la dirección de madres en busca de sus hijas e hijos. En el periodo de 2016-2019 el colectivo localizó al menos 125 fosas, con 298 cráneos y 22 mil restos óseos en el predio de 10 hectáreas de Colinas de Santa Fe, Veracruz, hasta ahora la fosa más grande de México (DAYÁN, 2019). La entereza de las mujeres que integran esta agrupación generó tal presión hacia la Fiscalía del estado y las autoridades federales que logró influir en que la acusación del exgobernador Javier Duarte no solo fuera por lavado de dinero y asociación delictuosa, sino por los crímenes de desaparición forzada.

Desde 2012 los colectivos de familias Madres Unidas por Nuestros Hijos San Fernando, Mylynali Red y Red de Desaparecidos en Tamaulipas localizaron, documentaron y alertaron a las autoridades del primer sitio de exterminio en México, hasta el momento se han detectado al menos 57 en el suroeste, centro y norte del país. Gracias a la documentación recogida por éstos se cuenta con la certeza que durante cinco años el gobierno federal (encabezado por Peña Nieto) y el estatal de Tamaulipas ocultaron la existencia del campo de exterminio de La Bartolina, el cual fue descubierto en 2016 por soldados. El 7 de julio de 2021, la Comisión Nacional de Búsqueda aceptó la existencia de dicho lugar, la comisionada Karla Quintana Osuna aseguró que es el más grande del país hasta ahora registrado. La denominación sitios de extermino fue acuñado por las familias buscadoras para asignar los espacios operados por los grupos criminales que van más allá de ser solo fosas clandestinas, pues incluyen campamentos de la delincuencia adaptados como dormitorios y comedores, área de homicidio y privación ilegal de la libertad de personas, botes usados como incineradores ilegales de cuerpos, así como un sector de destrucción y ocultamiento de evidencias bajo tierra, hojarasca o ramas de árboles. Las familias han declarado que los sitios de exterminio han tenido intervención parcial de la Fiscalía General de la República y las autoridades estatales en lo relativo a las búsquedas y levantamientos de restos, pero lo más preocupante es que no están siendo vigilados ni resguardados (JUÁREZ, ELEFANTE BLANCO Y A DÓNDE VAN LOS DESAPARECIDOS, 2021).

Frente a los hechos expuestos el colectivo Mylynali Red elaboró y presentó en 2020 el primer Protocolo Estandarizado de Búsqueda Ciudadana en Sitios de Exterminio, al momento ha sido aplicado en seis lugares de la zona de El Mante, Tamaulipas. El documento apunta a la necesidad de distinguir los sitios de exterminio de las fosas clandestinas, por lo que necesitan métodos y técnicas científicas 
particulares, que responden a una zona geográfica específica. Este instrumento se suma a los trabajos realizados por todo el país desde distintas iniciativas ciudadanas con el fin de abrir a debate público la discusión sobre las implicaciones de estas zonas (PÉREZ RODRÍGUEZ, LÓPEZ CERÓN Y PÉREZ RUÍZ, 2020).

\section{LA RESPUESTA INSTITUCIONAL: LA GUARDIA NACIONAL}

El triunfo histórico y esperanzador en 2018 del presidente Andrés Manuel López Obrador obtuvo el respaldo de un $53.19 \%$ de los votos ${ }^{10}$. El mandatario denunciaba la corrupción y se manifestaba en contra del uso de la violencia para combatir la inseguridad pública, principalmente del crimen organizado. Para responder a los hechos el gobierno de la autodenominada Cuarta Trasformación formuló en el Plan Nacional de Paz y Seguridad 2018-2024 los siguientes objetivos:

a) erradicar la corrupción y reactivar la justicia; b) garantizar el empleo, educación, salud y bienestar; c) respetar y promocionar los derechos humanos, en especial formar personal que integren las corporaciones policiacas y militares; d) reintegración ética de la sociedad, en el ámbito de la seguridad pública y combate a la delincuencia organizada, esto significa la utilización de métodos pacíficos y la confianza en el buen comportamiento de la mayoría de las personas; e) reformular el combate a las drogas, reconsiderar la prohibición de ciertos estupefacientes para atacar la capacidad operativa de la delincuencia organizada con el fin de reducir la violencia; f) emprender la construcción de la paz, proponer mecanismos de justicia transicional que garanticen los derechos de las víctimas, iniciar procesos de desmovilización, desarme y reinserción, del mismo modo instituir un Consejo de Construcción de Paz para que, entre otras cosas, promueva la participación ciudadana; g) recuperar y dignificar las cárceles: $h$ ) repensar la seguridad pública, seguridad nacional y paz: se admite que dada la descomposición social y la ineficacia de las corporaciones policiales resultaría desastroso relevar a las fuerzas armadas de su encomienda actual en materia de seguridad pública. Como parte final del Plan, se dio apertura a la observancia y participación de organismos de la sociedad civil y defensa de los derechos humanos nacionales e internacionales. Por último, se asignó a la Guardia Nacional como el instrumento primordial del Ejecutivo Federal en la prevención del delito, la preservación de la seguridad pública, la recuperación de la paz y el combate a la delincuencia (LÓPEZ OBRADOR, 2018c).

\footnotetext{
${ }^{10}$ La Lista nominal de 2018 destacó que el Padrón Electoral registró un total de 89, 250, 881 personas con la capacidad de ejercer el voto. Con un total de $63.4290 \%$ de participación ciudadana, equivalente a 56,611, 027 votos la coalición Juntos Haremos Historia (Morena, Partido del Trabajo y Encuentro Social) sumó el total de votos de 30, 113, 483 (INSTITUTO NACIONAL ELECTORAL, 2018).
} 
Definida como una institución de seguridad, de carácter civil, disciplinada y profesional, la Guardia Nacional tiene como objetivo "realizar la función de seguridad pública a cargo de la Federación $y$, en su caso, conforme a los convenios que para tal efecto se celebren, colaborar temporalmente en las tareas de seguridad pública que corresponden a las entidades federativas o municipios" (LEY DE LA GUARDIA NACIONAL, 2019). Este órgano policial actualmente depende de la Secretaría de Seguridad Pública y Protección Ciudadana, pero en la Estrategia Nacional de Seguridad Pública (2019) se advierte que serán las Fuerzas Armadas las que tendrán un papel protagónico en la formación, estructuración y capacitación de este organismo, pues se tomarán las fortalezas militares al aprovechar sus recursos humanos, materiales e infraestructura en favor de la seguridad. En julio de 2021, López Obrador anunció la construcción de nuevas instalaciones, así como el incremento de elementos y presupuesto de 50 mil millones de pesos para dicha institución con el fin de fortalecer y aumentar su presencia en el territorio nacional. Aun así, el mandatario aseguró que México no se está militarizando, pues en otros países como España, Italia o Francia las guardias nacionales dependen de las fuerzas armadas.

\section{EL FRACASO DEL ESTADO MEXICANO EN MATERIA DE SEGURIDAD PÚBLICA}

El discurso del proyecto político de la Cuarta Transformación se ha perfilado por la recuperación del tejido social al atacar las causas socioeconómicas que llevan a la inseguridad, por ello se han emprendido acciones para contrarrestar el desempleo, la pobreza y la desintegración familiar con el fin de sustituir al narcotráfico como una opción económica para la juventud, por expectativas de educación y trabajo honesto (becas como Jóvenes construyendo el futuro o Jóvenes escribiendo el futuro) (LÓPEZ OBRADOR, 2018d). Sin embargo, si la política social no va acompañada de una frontal estrategia nacional de seguridad y pacificación continuara la incapacidad estatal de combatir la inseguridad.

El Estado mexicano está colapsado en materia de seguridad pública, el paisaje es desolador al evidenciarse el incumplimiento del pacto social, pues son las crisis en materia forense y desaparición de personas las que reflejan el fracaso. Los desafíos acumulados durante varias décadas son complejos y las soluciones no pueden darse de forma homogénea, cada región cuenta con diversos retos que deben resolverse en términos de justicia social. Más no se trata solo de recriminar al pasado, la realidad es que la inseguridad es presente y el gobierno de López Obrador no ha mostrado resultados visibles. Si bien, la responsabilidad es compartida entre la autoridad federal, la estatal y las correspondientes 
fiscalías, la estrategia de utilizar a la Guardia Nacional no ha derivado en el cese de la violencia en el territorio nacional.

Abel Jesús Barrera Hernández, director del Centro de Derechos Humanos de la Montaña Tlachinollan, observa la prioridad de asignar mayor presupuesto a la Guardia Nacional, pero destaca que en los tres años del gobierno de la Cuarta Transformación los resultados en seguridad son imperceptibles. Peor aún, en lugares como la Sierra de Guerrero se ha solicitado el cuerpo de seguridad porque hay comunidades que sufren conflictos agrarios y enfrentamientos entre grupos de la delincuencia, pero no ha sido enviado. Para el defensor, la Guardia Nacional no tiene presencia donde se requiere una intervención apremiante para contrarrestar el clima de violencia y desactivar los focos rojos (BARRERA HERNÁNDEZ, 2021).

Entre el 15 y 26 de noviembre de 2021 el Comité contra la Desaparición Forzada de la ONU visitó por primera vez el país e indicó que "impera la impunidad casi absoluta", que favorece la reproducción y el encubrimiento de las desapariciones forzadas, así como la revictimización. La instancia especializada argumentó que para "que en México la desaparición deje de ser el paradigma del crimen perfecto" deben atacarse las causas, entre ellas: la ineficiencia en las investigaciones; la actitud negativa en el proceso de búsqueda de las fiscalías estatales, así como las inercias del pasado dentro del sistema procesal penal. Las y los comisionados subrayaron que "el enfoque de seguridad que se ha adoptado no solo es insuficiente, sino además inadecuado" y sugirieron la necesidad de crear una política nacional de prevención para erradicar la desaparición, la coordinación entre autoridades y la expansión de las atribuciones de las comisiones de búsqueda tanto nacional como estatales, porque a pesar de los avances legislativos e institucionales ${ }^{11}$ su aplicación es ineficiente (COMITÉ CONTRA LA DESAPARICIÓN FORZADA, 2021). Pues no es suficiente el "reconocimiento constitucional o normativo de los derechos fundamentales, son indispensables políticas públicas y mecanismos de garantía que los hagan efectivos" (ZAZUETA CARRILLO, 2014, p. 15). Dado que si no se cumplen materialmente los deberes del Estado los actos corrosivos se pueden repetir y la impunidad imperar.

Para superar este drama el Comité enfatizó que se requiere voluntad política, participación y reparación de las víctimas con un enfoque de género y multicultural, recursos financieros suficientes y personal capacitado, competente y comprometido. Finalmente, señaló que se ha trasladado la

\footnotetext{
${ }^{11}$ De los que destacan la Ley General de Víctimas, el Protocolo Homologado de Búsqueda, el Protocolo Adicional para la Búsqueda de Niños, Niñas y Adolescentes, el Mecanismo Extraordinario de Identificación Forense, la Comisión para el Acceso a la Verdad, el Esclarecimiento Histórico y el Impulso a la Justicia de las violaciones graves a los derechos humanos cometidas de 1965 a 1990, Mecanismo Transnacional de Acceso a la Justicia para Migrantes, entre otros.
} 
responsabilidad de investigar y aportar pruebas a las víctimas (COMITÉ CONTRA LA DESAPARICIÓN FORZADA, 2021). Incluso en 2019 el propio visitador de la Comisión Nacional de Derechos Humanos, Ismael Eslava Pérez declaró que "hay un problema estructural en materia de procuración de justicia. Corresponde la búsqueda, localización y sanción a las autoridades, [pero] este trabajo ha sido sustituido por el trabajo de los colectivos de familiares de personas desaparecidas" (SOBERANES, 2019). El activismo de los colectivos de víctimas ha delatado la incapacidad, negligencia y omisión del Estado en materia de seguridad pública, desaparición de personas y forense, pues sus acciones han llegado a remplazar y cubrir las obligaciones que les corresponden a las instancias gubernamentales.

\section{A MODO DE CONCLUSIÓN}

Las instituciones estatales no solo están preparadas para proporcionar seguridad física, sino que tiene las condiciones para evitar que la vida de la población transcurra como si el Estado no existiera en la fragilidad irruptora de considerar que hacerse justicia por sí mismo fuese una opción moral y jurídicamente válida en caso de ineficiencia. A pesar de las condiciones actuales de inseguridad pública en México, el Estado es el único ente que puede asegurar la paz social y el orden, pero requiere una transformación institucional acompañada y supervisada por la ciudadanía. Como quedó asentado no se puede suplir la función estatal de garantizar seguridad pública, pero es gracias a la democracia participativa que la ciudadanía se convierte en un cause alternativo de acceso a la justicia de manera horizontal, bajo los límites de la legalidad. Las organizaciones de víctimas se asumen como un sujeto político colectivo que inciden en la toma de decisiones y en la corrección de las ineficiencias del Estado. El trabajo del Movimiento por Nuestros Desaparecidos en México, Colectivo el Solecito de Veracruz, Madres Unidas por Nuestros Hijos San Fernando, Mylynali Red, Red de Desaparecidos en Tamaulipas y Familias Unidas demuestra la capacidad organizativa y el ejercicio de su ciudadanía para contribuir a la defensa y promoción de los derechos humanos, los derechos de las víctimas y la visibilización de las personas desaparecidas. 


\section{REFERENCIAS BIBLIOGRÁFICAS}

AGUAYO, Sergio; DAYÁN, Jacobo. El Yugo Zeta. Norte de Coahuila, 2010-2011. México: El Colegio de México, 2018. Disponible en:

https://www.gob.mx/cms/uploads/attachment/file/274076/El_yugo_Zeta_FINAL_11-16-17.pdf

BAQUÉS QUESADA, Josep. Los grupos armados sub-estatales como fuente de inestabilidad: walords, jefes de clan, milicias. Actores armados no estatales: retos a la seguridad global, España: Instituto Español de Estudios Estratégicos, n. 152, p.101-130, 2011. Disponible en:

http://www.ieee.es/Galerias/fichero/cuadernos/CE_152_ActoresArmadosNoEstatales.pdf

BARRERA HERNÁNDEZ, Abel Jesús. Guerrero: Corte de Caja del año 2021, DH ¿mejor, peor o igual? ¿Por qué? Rompeviento TV, YouTube, 29 de diciembre de 2021. Disponible en:

https://www.youtube.com/watch?v=HHTt6Z5tXdY\&t=4s

CARRILLO CASTILLO, Lucy. Tomas Hobbes y el concepto de Estado constitucional de derecho. Revista de Estudios Políticos, n. 117, p.249-273, jul./sep., 2002. Disponible en:

https://dialnet.unirioja.es/descarga/articulo/272259.pdf

CENTRO DE COLABORACIÓN CÍVICA. EI Movimiento por Nuestros Desaparecidos en México y su camino hacia la incidencia legislativa. La siembra colectiva, una apuesta por la esperanza. México: Senado de la República; MacArthur Foundation, 2018. Disponible en:

https://colaboracioncivica.org/uploads/LibroCCC_SisMNDM.pdf

CEPEDA, Ana; LEETOY, Salvador. De víctimas a expertas: estrategias de agencia cívica para la identificación de desaparecidos en México. Iconos. Revista de Ciencias Sociales, n. 69, vol. XXV, p. 181-200, ene./ abr. 2021. Disponible en: https://doi.org/10.17141/iconos.69.2021.4197

COLECTIVO SOLECITO DE VERACRUZ. Madres que luchan con amor por sus hijos iHasta encontrarlos! 2021. Disponible en: https://www.idheas.org.mx/colectivo-solecito-de-veracruz/

COMISIÓN ESTATAL DE DERECHOS HUMANOS DE VERACRUZ, Derechos de los familiares de personas desaparecidas. México: CEDHV, 2016. Disponible en:

http://cedhvapp2.sytes.net:8080/derechos_humanos/file.php/1/Campanas_2016/DDdesaparecidos/ Derechos_de_los_familiares_de_las_personas_desaparecidas.pdf

COMISIÓN NACIONAL DE DERECHOS HUMANOS. Recomendación No. 23VG/2019. México: CNDH, 2019. Disponible en: https://www.cndh.org.mx/sites/default/files/documentos/2019-

10/REC_2019_23VG.pdf

COMISIÓN NACIONAL DE BÚSQUEDA. Versión Pública RNPDNO. 2021. Disponible en: https://versionpublicarnpdno.segob.gob.mx/Dashboard/Index

COMITÉ CONTRA LA DESAPARICIÓN FORZADA. Comunicado de prensa: "Es necesario que México adopte una política nacional de prevención para erradicar la desaparición", 26 de noviembre de 2021. Disponible en: https://www.onu.org.mx/es-necesario-que-mexico-adopte-una-politicanacional-de-prevencion-para-erradicar-la-desaparicion/ 
CONSEJO CIUDADANO PARA LA SEGURIDAD PÚBLICA Y LA JUSTICIA PENAL. Ranking 2020 de las $\mathbf{5 0}$ ciudades más violentas del mundo. 20 de abril de 2021. Disponible en:

http://www.seguridadjusticiaypaz.org.mx/sala-de-prensa/1597-metodologi-a-del-ranking-2020-delas-50-ciudades-ma-s-violentas-del-mundo

CONSEJO MEXICANO DE LAS CIENCIAS SOCIALES. 5to Congreso Nacional de Ciencias Sociales. La agenda emergente de las Ciencias Sociales. Conocimiento, Crítica e Intervención. México: Universidad de Guadalajara, 2016. Disponible en: https://www.comecso.com/5congreso/EJE1.pdf

CONSTITUCIÓN POLÍTICA DE LOS ESTADOS UNIDOS MEXICANOS. Disponible en:

https://www.diputados.gob.mx/LeyesBiblio/pdf/CPEUM.pdf

CRISIS GROUP. La guerra cotidiana: Guerrero y los retos a la paz en México. REPORT 80 / LATIN AMERICA \& CARIBBEAN, 4 de mayo de 2020. Disponible en: https://www.crisisgroup.org/es/latinamerica-caribbean/mexico/80-mexicos-everyday-war-guerrero-and-trials-peace

DAYÁN, Jacobo. La fosa más grande del país: Colinas de Santa Fe. Aristegui Noticias, 9 de agosto 2019. Disponible en: https://aristeguinoticias.com/0908/mexico/la-fosa-mas-grande-del-pais-colinasde-santa-fe-articulo/

DUSSEL, Enrique. Lo político y la democracia en ÁVALOS TENORIO, Gerardo Coord. Redefinir lo político. México: Universidad Autónoma Metropolitana, 2002.

EJÉRCITO ZAPATISTA DE LIBERACIÓN NACIONAL. Comunicado del Comité Clandestino Revolucionario Indígena-comandancia General del Ejército Zapatista de Liberación Nacional, Chiapas al borde de la Guerra Civil, 19 de septiembre de 2021. Disponible en: https://enlacezapatista.ezln.org.mx/2021/09/19/chiapas-al-borde-de-la-guerra-civil/

ENCINAS, Alejandro. Búsqueda e Identificación de Personas desaparecidas. México: Secretaría de Gobernación, Subsecretaria de Derechos Humanos, Población y Migración, 8 de abril 2021. Disponible en: http://www.alejandroencinas.mx/wpcontent/uploads/2021/04/INFORMEB\%C3\%9ASQUEDA8ABRIL2021.pdf

ESTRATEGIA NACIONAL DE SEGURIDAD PÚBLICA. México: Diario Oficial de la Federación, 16/05/2019. Disponible en:

https://www.dof.gob.mx/nota_detalle.php?codigo=5560463\&fecha=16/05/2019

ETELLEKT CONSULTORES. Sexto Informe de Violencia Política en México 2021. Junio de 2021. Disponible en: https://www.etellekt.com/informe-de-violencia-politica-en-mexico-2021-J5etellekt.html

FLORES MARTÍNEZ, Alejandra; URIBE ARZATE, Enrique. La superación del monopolio proteccionista de los derechos humanos en el estado constitucional mexicano, a partir de la reforma al artículo primero constitucional. Vniversitas, Bogotá, Colombia, n. 129, p. 103-133, jul/dic. 2014. Disponible en: http://dx.doi.org/10.11144/Javeriana.VJ129.smpd

FRANCO, Darwin; GONZÁLEZ, Fara; TAPIA GALLARDO, Fernanda Aranza; VARGAS, Samantha. Jalisco: La verdad de los "tráileres de la muerte". A DÓNDE VAN LOS DESAPARECIDOS. 17 de septiembre de 
2020. Disponible en: https://adondevanlosdesaparecidos.org/2020/09/17/jalisco-la-verdad-de-lostraileres-de-la-muerte/

GUERRA MANZO, Enrique. Las autodefensas de Michoacán. Movimiento social, paramilitarismo y neocaciquismo. Política y Cultura. Universidad Autónoma Metropolitana Unidad Xochimilco, México, n. 44, p. 7-31, otoño 2015. Disponible en: https://www.redalyc.org/pdf/267/26743130002.pdf

GUILLÉN, Alejandra; TORRES, Mago; TURATI, Marcela. El país de las 2 mil fosas. Quinto Elemento Lab, 12 de noviembre de 2018. Disponible en: https://quintoelab.org/project/el-pais-de-las-2-milfosas

GRAYSON, George W. México: Narco-Violence and a Failed State? New York, London: Transaction Publishers, New Brunswick, 2010.

HERNÁNDEZ NAVARRO, Luis; BARRERA HERNÁNDEZ, Abel Jesús. Desde el corazón de la montaña. México: Brigada Para leer en libertad, 2020. Disponible en:

https://brigadaparaleerenlibertad.com/documents/public/books_file/desde-la-montana.pdf

HOBBES, Thomas. Leviatán, México: Fondo de Cultura Económica, 2010.

HUMAN RIGHTS WATCH. Los desaparecidos en México. El persistente consto de una crisis ignorada. 20 de febrero de 2013a. Disponible en: https://www.hrw.org/es/report/2013/02/20/losdesaparecidos-de-mexico/el-persistente-costo-de-una-crisis-ignorada

HUMAN RIGHTS WATCH. México el decepcionante primer año del gobierno de Peña Nieto. 26 de noviembre de 2013b. Disponible en: https://www.hrw.org/es/news/2013/11/26/mexico-eldecepcionante-primer-ano-del-gobierno-de-pena-nieto

INSTITUTO MEXICANO DE DERECHOS HUMANOS Y DEMOCRACIA. Dignificando la memoria. La desaparición de personas en Veracruz, Ciudad de México, agosto 2019. Disponible en: https://www.gob.mx/cms/uploads/attachment/file/598933/Dignificando-lamemoria_unlocked_esteril.pdf

INSTITUTO NACIONAL ELECTORAL. Cómputos Distritales 2018 Elecciones Federales. México, 8 de julio de 2018. Disponible en: https://computos2018.ine.mx/\#/presidencia/nacional/1/1/1/1

JUÁREZ, Carlos Manuel; ELEFANTE BLANCO; A DÓNDE VAN LOS DESAPARECIDOS. Colectivos de familiares han localizado 57 sitios de exterminio en Tamaulipas. 27 de julio 2021. Disponible en: https://adondevanlosdesaparecidos.org/2021/07/27/colectivos-de-familiares-han-localizado-57sitios-de-exterminio-en-tamaulipas/

LEY DE LA GUARDIA NACIONAL. México: Diario Oficial de la Federación, 27/05/2019. Disponible en: http://www.diputados.gob.mx/LeyesBiblio/pdf/LGN_270519.pdf

LEY DE PARTICIPACIÓN CIUDADANA DE LA CIUDAD DE MÉXICO, 08/2019. Disponible en: http://www.contraloria.cdmx.gob.mx/docs/1908_LeyParticipacionCiudadanaN.pdf 
LEY DE RECONOCIMIENTO, DERECHOS Y CULTURA DE LOS PUEBLOS Y COMUNIDADES INDÍGENAS DEL ESTADO DE GUERRERO, 2011. Disponible en

https://congresogro.gob.mx/legislacion/ordinarias/ARCHI/LEY-DE-RECONOCIMIENTO-DERECHOS-YCULTURA-DE-LOS-PUEBLOS-Y-COMUNIDADES-INDIGENAS-DEL-ESTADO-DE-GUERRERO-701-2021-0310.pdf

LOBORIE IGLESIAS, Mario A. Actores armados no estatales, en Actores armados no estatales: retos a la seguridad global. España: Instituto Español de Estudios Estratégicos, n. 152, p. 27-64, 2011.

Disponible en:

https://www.ieee.es/Galerias/fichero/cuadernos/CE_152_ActoresArmadosNoEstatales.pdf

LÓPEZ OBRADOR, Andrés Manuel. Conferencia matutina, YouTube, 2 de julio de 2021a. Disponible en: https://www.youtube.com/watch?v=fonU8zoMxn8

LÓPEZ OBRADOR, Andrés Manuel. Conferencia matutina, YouTube, 15 de julio de 2021b. Disponible en: https://www.youtube.com/watch?v=DCYdUuTPhNg

LÓPEZ OBRADOR, Andrés Manuel. Plan Nacional de paz y seguridad 2018-2024. 2018c. Disponible en: https://lopezobrador.org.mx/wp-content/uploads/2018/11/PLAN-DE-PAZ-Y-

SEGURIDAD_ANEXO.pdf

LÓPEZ OBRADOR, Andrés Manuel. Proyecto de Nación 2018-2024. 2018d. Disponible en: https://contralacorrupcion.mx/trenmaya/assets/plan-nacion.pdf

MÉXICO EVALÚA; CENTRO DE ANÁLISIS DE POLÍTICAS PÚBLICAS. Hallazgos 2018: Seguimiento y Evaluación del Sistema de Justicia Penal en México. México: 2019. Disponible en: https://www.mexicoevalua.org/mexicoevalua/wp-content/uploads/2020/03/hallazgos2018-3.pdf

MVDM. El Movimiento y los colectivos. 2021. Disponible en: https://memoriamndm.org/sobre-elmovndmx/

OCAMPO ARISTA, Sergio. Se integran 31 niños a policía comunitaria de Guerrero. 11 de abril de 2021. Disponible en: https://videos.jornada.com.mx/media/videos/59016414.mp4

OFICINA DEL ALTO COMISIONADO DE LAS NACIONES UNIDAS PARA LOS DERECHOS HUMANOS.

Violencia e inseguridad. (s/f). Disponible en: http://www.oacnudh.org/areas-de-trabajo/seguridadciudadana/

ORDÓÑEZ, Joaquín. Hacia una concepción del juicio democrático 'lato sensu' y del juzgador democrático en México desde la teoría del coto vedado. Revista de Direito da Cidade, vol. 9, n. 4, p. 1626-1651, 2017. Disponible en: https://doi.org/10.12957/rdc.2017.29772

PAREDES, Heriberto. Michoacán: una comunidad en armas. México: México Evalúa, 14 de septiembre 2021. Disponible en: https://www.mexicoevalua.org/michoacan-una-comunidad-enarmas-para-plantar-platanos/

PÉREZ RODRÍGUEZ, Graciela; LÓPEZ CERÓN, Sara; PÉREZ RUÍZ, Evencio. Protocolo Estandarizado de Búsqueda Ciudadana en Sitios de Exterminio. Mylynali Red. Buscando a nuestros amados desaparecidos. 2020. Disponible en: https://www.milynaliredcfc.org/protocolo-de-busqueda 
ROUX, Rhina. La política de los subalternos en ÁVALOS TENORIO, Gerardo Coord. Redefinir lo político. México: Universidad Autónoma Metropolitana, 2002.

SALDAÑA FLORES, Alejandro. La barbarie sin fin. Una hidra de mil cabezas. Rompeviento TV, 10 de enero de 2022. Disponible en: https://www.rompeviento.tv/la-barbarie-sin-fin-una-hidra-de-milcabezas/

SÁNCHEZ ESPINOZA, Francisco; JUÁREZ JAIMES, Claudia. Política de seguridad en México: combate al narcotráfico. Entre la seguridad nacional y la seguridad pública. Revista IUS, Puebla, vol.13, n. 44, p. 229-250, 2019. Disponible en: http://www.scielo.org.mx/scielo.php?script=sci_arttext\&pid=S187021472019000200229\&Ing=es\&nrm=iso

SÁNCHEZ VALDÉS, Víctor Manuel; PÉREZ AGUIRRE, Manuel; VERÁSTEGUI GONZÁLEZ, Jorge. Formación y Desarrollo de los Colectivos de Búsqueda de personas desaparecidas en Coahuila: lecciones para el futuro. México: El Colegio de México, 2018. Disponible en:

https://violenciaypaz.colmex.mx/assets/docs_pubs/original/29/Formacion_y_desarrollo_de_los_col ectivos.pdf?1580251978

SECRETARÍA DE SEGURIDAD Y PROTECCIÓN CIUDADANA. Informe de Seguridad, mayo 2021.

Disponible en: http://www.informeseguridad.cns.gob.mx/

SESNSP. Informe de Incidencia Delictiva de Fuero Común. noviembre 2021. Disponible en:

https://drive.google.com/file/d/1APZGEjH52_xMq_illLGr6b3fcYX9-om2/view

SESNSP. Informe de Incidencia Delictiva de Fuero Común, 2019. Disponible en:

https://drive.google.com/file/d/1g2HCuXR8vODs_UsnUSwWyE_Kc8Im5yme/view

SOBERANES, Rodrigo. Nada impide a una madre seguir buscando: Colectivo Solecito mantendrá así su labor. Animal Político, 12 de agosto de 2019. Disponible en:

https://www.animalpolitico.com/2019/08/colectivo-solecito-busqueda-restos/

THOMPSON, Ginger. Anatomía de una masacre. ProPublica; National Geographic, 12 de junio de 2017. Disponible en: https://www.propublica.org/article/allende-zetas-cartel-masacre-y-la-dea

TORRES CARRILLO, Alfonso. Las lógicas de la acción colectiva. Aportes para ampliar la comprensión de los movimientos sociales, Colombia: Universidad Pedagógica Nacional. Especialización en Teorías, Métodos y Técnicas de Investigación, 2005. Disponible en:

https://aprendeenlinea.udea.edu.co/Ims/moodle/file.php/180/Seminario_Investigacion_y_Movimie ntos_Sociales/Ponencias_centrales/Ponencia_Alfonso_Torres.pdf

VILLARREAL MARTínEZ, María Teresa. Respuestas ciudadanas ante la desaparición de personas en México (2000-2013). Espacios Públicos, Universidad Autónoma del Estado de México, Toluca, México, vol. 17, n. 39, p. 105-135, ene/abr., 2014. Disponible en:

https://www.redalyc.org/pdf/676/67630574007.pdf

ZAZUETA CARRILLO, Laura Wendy. El derecho a la verdad en el marco de la justicia transicional como obligación del Estado mexicano ante la impunidad. Via Inveniendi Et ludicandi, Universidad Santo Tomás Bogotá, Colombia vol. 9, n.2, p. 11-39, jul-dic. 2014. Disponible en:

https://www.redalyc.org/pdf/5602/560258676002.pdf 


\begin{abstract}
Sobre as autoras:
Mónica Natalia Martínez Mejía

Doctora y Maestra en Estudios Jurídicos, Licenciada en Derecho por la Universidad Autónoma del Estado de México. Es Técnica Judicial (auxiliar proyectista) en la Primera Sala Colegiada Civil de Toluca del Tribunal Superior de Justicia del Estado de México. Universidad Autónoma del Estado de México.Toluca de Lerdo, Méx., México. ORCID: https://orcid.org/0000-0001-9432-3342

E-mail: nataliammejia@gmail.com

\section{Fátima Esther Martínez Mejía}

Maestra en Humanidades y Licenciada en Derecho por la Universidad Autónoma del Estado de México. Doctoranda en Estudios Latinoamericanos por la misma casa de estudios y docente a nivel licenciatura. Universidad Autónoma del Estado de México,Toluca de Lerdo, Méx., México.

ORCID: https://orcid.org/0000-0003-2882-4346

E-mail: fatimaemmejia@hotmail.com

As autoras contribuíram igualmente para a redação do artigo.
\end{abstract}

